\title{
A Permutation-Randomization Approach to Test the Spatial Distribution of Plant Diseases
}

\author{
G. Lione and P. Gonthier
}

Department of Agricultural, Forest and Food Sciences, University of Torino, Largo P. Braccini 2, 10095 Grugliasco, Italy. Accepted for publication 5 October 2015.

\begin{abstract}
Lione, G., and Gonthier, P. 2016. A permutation-randomization approach to test the spatial distribution of plant diseases. Phytopathology 106:19-28.

The analysis of the spatial distribution of plant diseases requires the availability of trustworthy geostatistical methods. The mean distance tests (MDT) are here proposed as a series of permutation and randomization tests to assess the spatial distribution of plant diseases when the variable of phytopathological interest is categorical. A user-friendly software to perform the tests is provided. Estimates of power and type I error, obtained with Monte Carlo simulations, showed the reliability of the MDT (power $>0.80$; type I error $<0.05$ ). A biological validation on the

spatial distribution of spores of two fungal pathogens causing root rot on conifers was successfully performed by verifying the consistency between the MDT responses and previously published data. An application of the MDT was carried out to analyze the relation between the plantation density and the distribution of the infection of Gnomoniopsis castanea, an emerging fungal pathogen causing nut rot on sweet chestnut. Trees carrying nuts infected by the pathogen were randomly distributed in areas with different plantation densities, suggesting that the distribution of G. castanea was not related to the plantation density. The MDT could be used to analyze the spatial distribution of plant diseases both in agricultural and natural ecosystems.
\end{abstract}

Analyzing the spatial pattern of plant diseases may be pivotal to elucidate the ecology, the epidemiology, and the infection biology of pathogens as well as the mechanisms underlying host-pathogen interactions and the spread of epidemics (Nelson et al. 1999). A large body of literature deals with the application of geographic information systems (GIS) in conjunction with statistical and geostatistical methods to investigate peculiar traits of plants diseases, to test biologically relevant hypotheses and to build predictive and/or explicative models (Nelson et al. 1999). Examples of GIS and geostatistical applications can be found in both agriculture and forestry on a broad range of diseases, hosts, and pathogens, including viruses, bacteria, and fungi. For instance, GIS and geostatistical analyses were used to investigate the dispersal mechanisms of pathogens, to explore the spatial distribution of the genotypes within pathogens populations, to model the spatiotemporal dynamics of the spread of infectious diseases, to assess the spatial pattern of symptoms, to test the association between soil, climate, habitat and the disease incidence, and to define adequate management prescriptions to thwart biological invasions (Chellemi et al. 1988; Gonthier et al. 2012, 2014; Gottwald et al. 1995; JaimeGarcia et al. 2000; Lamichhane et al. 2013; Lione et al. 2015; Nelson et al. 1999; Pizzato et al. 2014).

As shown in this overview, regardless of the spatial scale of the study and of the pathosystem under investigation, many experimental designs in plant pathology are characterized by a recurring pattern. Within this pattern, points (e.g., individual plants, sampling sites, or spore trapping devices) are defined by spatial coordinates and by a variable of phytopathological relevance. This variable can be either quantitative (e.g., disease incidence, disease severity, and amount of inoculum) or categorical (e.g., infected/healthy plant,

Corresponding author: P. Gonthier; E-mail address: paolo.gonthier@unito.it

*The $\boldsymbol{e}$-Xtra logo stands for "electronic extra" and indicates that two supplementary files are published online.

http://dx.doi.org/10.1094/PHYTO-05-15-0112-R

(C) 2016 The American Phytopathological Society plant showing heavy/moderate/mild symptoms, and infested/not infested site). The analysis of the spatial distribution of points and of the associated variable relies on different conceptual and computational approaches.

Several methods are available to assess whether the spatial distribution of points is clustered, random or dispersed, including the nearest neighbor index (NNI), the F-function, the G-function, the Ripley's K-function, the L-function, and the nearest neighbor hierarchical clustering (NNHC), whose significance is generally estimated with Monte Carlo (MC) simulations (Mitchell 2009; Szmyt 2014). The rationale of MC simulations lies in the comparison between the observed points location and the location of a large number of points samples drawn from a predefined data generating process (DGP) known as point process (Carsey and Harden 2014; Crawley 2013). The choice of the appropriate point process depends upon the null hypothesis being tested (de Smith et al. 2007).

The spatial distribution of the quantitative variable associated with points is generally assessed through spatial autocorrelation analyses involving the Mantel test, the spatial analysis by distance indices (SADIE) methodology, the estimation of variograms, and the calculation of autocorrelation indexes such as the Geary's c, the Moran's I, and the Getis-Ord general G-statistic at global or local scale (Mantel 1967; Mitchell 2009; Perry and Hewitt 1991; Webster and Oliver 2001). To account for the stochastic uncertainty related to these methods, asymptotic theory and heuristic procedures are available (Goslee and Urban 2007; Marchant and Lark 2004; Mitchell 2009). While the above-cited techniques are routinely applied and embedded in some major GIS and statistical software (Mitchell 2009), the spatial distribution of a categorical variable associated with points is still a topic of active research and ongoing development. In the last decades plant pathologists have proposed and validated some conceptual and technical solutions to this issue. For instance, the software package 2DCLASS was designed to perform the Gray's analysis aimed at detecting the spatial pattern of plant diseases (Gray et al. 1986; Nelson et al. 1992). 2DCLASS was further improved by the STCLASS package (Nelson 1995) and by 
an MC-based approach to investigate the spatiotemporal pattern of the spread of epidemics (Thébaud et al. 2005). A correlation-based technique was also proposed to detect the spatial distribution of discrete data through the 2DCORR package (Ferrandino 1998). More recently, an extension of local measures of spatial association was suggested to deal with the same kind of data (Boots 2003). The above cited solutions were designed to analyze binomial categorical data (e.g., infected/healthy plant) in lattices, where points were approximated to cells in a regular grid, including missing points (e.g., missing plants). While this approximation is suitable to model many field conditions where plants are located in the space according to a predefined geometric pattern, like in nurseries, in orchards, and in regular plantations, no application to forestry, to irregular plantations, and to natural seedlings regeneration has been reported so far. Despite the fact that transiogram analyses were proposed to overcome the constraints related to the plants plantation scheme, the discrepancy between experimental transiograms and idealized ones can occur, affecting the interpretation of the results (Weidong 2006).

The goal of this study was to develop and validate a permutationand randomization-based approach, hereafter called mean distance tests (MDT), to assess the spatial pattern of a plant disease when this is defined as a categorical variable. The MDT algorithms were embedded in a user-friendly application for personal computer.

\section{MATERIALS AND METHODS}

Overview and software design. Let $T=\left\{t_{1}, t_{2}, \ldots, t_{n}\right\}$ be a finite set of $n$ points with known $x$ and $y$ coordinates in a Cartesian plane and let $I \subset T$ be a subset of $T$ including $m(2 \leq m \leq n-2)$ points. For instance, the points in the set $T$ could be plants and the points in the subset $I$ could be the plants infected by some pathogens. In other terms, the $m$ points in the subset $I$ are those points of the set $T$ which a level $\gamma$ (i.e., "infected") of a categorical variable $\Gamma$ (e.g., "health status") has been assigned to. Let $\bar{d}$ be an overall index of the distances that separate $m$ points in a plane, calculated as the mean of the values stored in the $m \times m$ triangular Euclidean distance matrix of the points. Let $\bar{d}_{0}$ be the observed value of $\bar{d}$, which is calculated for the $m$ points included in the subset $I$. Finally, let

$$
\left(\begin{array}{l}
n \\
m
\end{array}\right)
$$

be a binomial coefficient, representing the number of possible arrangements of $m$ elements drawn from a set of $n$ elements. Within the permutation test framework, the probability mass function (PMF) of $\bar{d}$ is obtained by calculating $\bar{d}$ for each $i^{\text {th }}$ combination

$$
\left[1 \leq i \leq\left(\begin{array}{c}
n \\
m
\end{array}\right)\right]
$$

through which $m$ points of the set $T$ can be randomly assigned to the subset I (Carsey and Harden 2014). Instead, within the randomization test framework, the PMF is estimated by calculating $\bar{d}$ on a random sample without replacement of $B$ combinations

$$
\left[1<B<\left(\begin{array}{c}
n \\
m
\end{array}\right)\right]
$$

(Carsey and Harden 2014). The main core of this work is to determine from the PMF, with a predefined significance level cutoff $\alpha$, whether $\bar{d}_{0}$ is either significantly lower (i.e., located toward the left tail) or higher (i.e., located toward the right tail) than the value expected under the random assignment of $\gamma$ (i.e., random definition of the subset $I$ within the set $T$ ). The first case indicates a clustered spatial pattern of the level $\gamma$, while the second occurs in a dispersed spatial pattern of the same level. This is equivalent to test if the infected plants are nearer or further apart than expected according to a random distribution of the infected plants within the sampled plants. To deal with this issue, the MDT approach is proposed here.

MDT are based on the assumption that the $x$ and $y$ coordinates of points in the set $T$ are fixed and that only the assignment of the level $\gamma$ is a stochastic process. The MDT consist of three permutation tests (mean distance permutation tests [MDPT], hereafter PT) and three randomization tests (mean distance randomization tests [MDRT], hereafter RT). Both permutation and randomization tests are divided according to the tails of the PMF they refer to (Hartwig 2013). MDPT2T is the two-tailed permutation test (hereafter $P_{2 T}$ ), MDPTLT the left-tailed (hereafter $\mathrm{P}_{\mathrm{LT}}$ ), and MDPTRT the righttailed (hereafter $\mathrm{P}_{\mathrm{RT}}$ ), respectively. Similarly, the RT are designed in the two-tailed version (MDRT2T, hereafter $\mathrm{R}_{2 \mathrm{~T}}$ ), in the left-tailed (MDRTLT, hereafter $\mathrm{R}_{\mathrm{LT}}$ ), and in the right-tailed (MDRTRT, hereafter $\mathrm{R}_{\mathrm{RT}}$ ) ones (Table 1). Once the above described steps to obtain the PMF and to calculate $\bar{d}_{0}$ are performed, the mean value $\bar{D}$ of the PMF is calculated, the exact $P$ value $\left(p_{e}\right)$ for PT and the randomization $P$ value $\left(p_{r}\right)$ for RT are determined as reported in Carsey and Harden (2014) and Ernst (2004). The adequacy of the number $B$ selected to perform the RT is assessed by calculating the lower $\left(L_{p r}\right)$ and upper $\left(U_{p r}\right)$ bounds of the confidence interval for $p_{r}$ at user-defined level $\lambda$ (e.g., 0.95). The confidence interval is

TABLE 1. For each test included in the mean distance tests the tail, the null hypothesis, the input required and the output provided are indicated ${ }^{\mathrm{a}}$

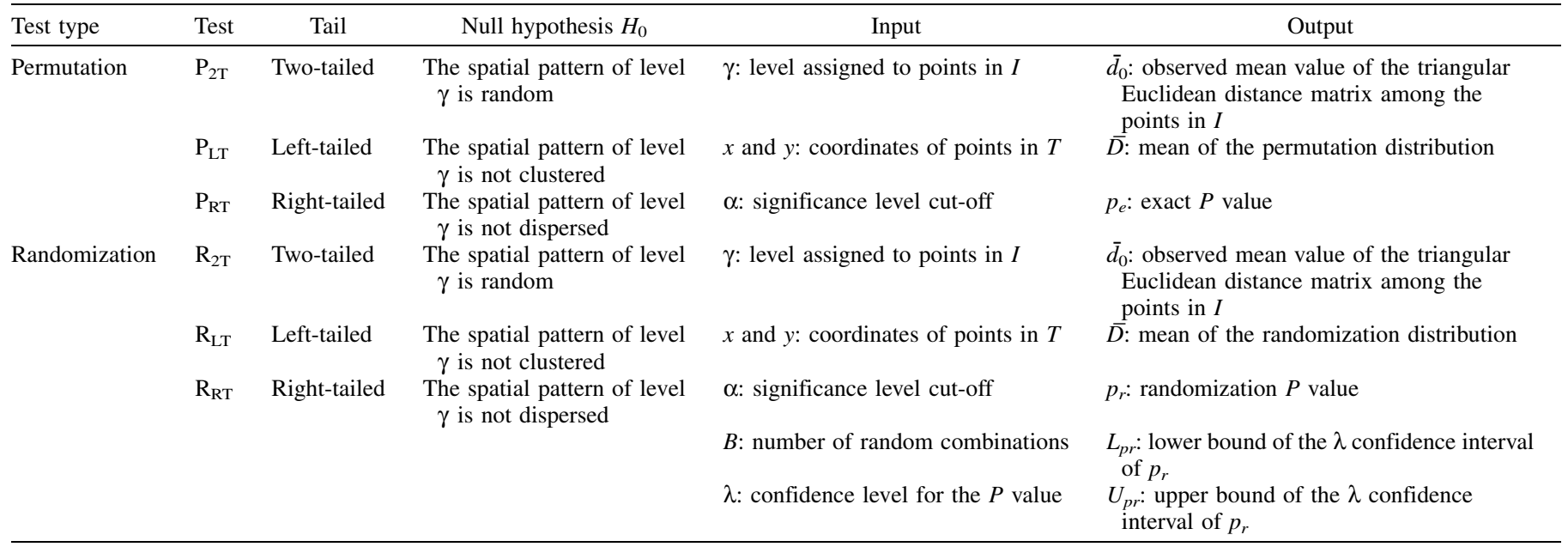

${ }^{a}$ Tests are divided according to the underlying resampling technique (test type) and identified by an acronym (test). 
obtained from the binomial distribution as described in Ernst (2004). Whenever the condition $L_{p r} \leq \alpha \leq U_{p r}$ is verified, $p_{r}$ is deemed to be ambiguous and $B$ is increased until the sampling adequacy is achieved and, thus, ambiguity is solved (Ernst 2004).

The algorithms performing the MDT were compiled and run in $\mathrm{R}$ 3.1.2 environment ( $\mathrm{R}$ Core Team, Vienna, Austria) and subsequently embedded in a software for personal computer designed with Shiny, a hybrid R-HTML environment (Beeley 2013).

MC estimates of PT power and type I error. MC simulations were performed to assess the power and the type I error of $\mathrm{P}_{2 \mathrm{~T}}, \mathrm{P}_{\mathrm{LT}}$, and $\mathrm{P}_{\mathrm{RT}}$. According to the null hypothesis of each test (Table 1), three DGPs were designed. Every DGP consisted in a point process inscribed in a circle, realized both in a squared $4 \times 4$ units window and in a $6 \times 6$ one, and replicated for two sample sizes. The point processes included $n=15$ points for the set $T$ and from $m=$ 2 to $m=13$ points for the subset $I$ in the first sample, while in the second sample size $n$ was 20 and $m$ ranged from 2 to 18 . The origin of the Cartesian system was located in the windows center and the points coordinates were expressed in polar form $(R, \theta)$. The first DGP (point process 1 - PP1) was designed to simulate a random spatial distribution of $\gamma$. At each MC simulation, the set $T$ was generated by sampling for $n$ times $R$ from a uniform distribution (Carsey and Harden 2014) bounded between 0 and half the window edge and $\theta$ from a uniform distribution bounded between 0 and $2 \pi$ radians. A random number generator was used to define the subset $I$ by drawing $m$ out of $n$ points without replacement, with the extraction probability set constant for each point (Carsey and Harden 2014). The level $\gamma$ was assigned to the sampled $m$ points. The second DGP (PP2) was planned to simulate a clustered spatial distribution of $\gamma$. The level $\gamma$ was assigned to $m$ points whose $R$ was sampled from a beta distribution with shape parameters $a=$ 0.5 and $b=10$ (Crawley 2013) and whose $\theta$ was generated from the same uniform distribution described for PP1. The remaining points were drawn in the same way but inverting the $a$ and $b$ shape parameters. In the last DGP (PP3), a dispersed spatial distribution of $\gamma$ was simulated. PP3 was set as described for PP2 with the exception of the shape parameters of the beta distribution, which were inverted.

To gather the estimates of PT power and type I error, two blocks of MC simulations (hereafter blocks), each one consisting in $1 \times$ $10^{4}$ simulations, were performed for both windows, for every $m$ value, and for any PT, resulting in $1.44 \times 10^{6}$ simulations for the first sample size ( 2 windows $\times 12 m$ values $\times 3$ tests $\times 2$ blocks $\times$ $10^{4}$ simulations) and $2.04 \times 10^{6}$ for the second sample size $(2$ windows $\times 17 m$ values $\times 3$ tests $\times 2$ blocks $\times 10^{4}$ simulations). For each block, either a single DGP or a couple of DGPs selected among PP1, PP2, and PP3 was run. The number of simulations based on PP1, PP2, or PP3 within a single block varied depending on the PT (Table 2). For every simulation within the block, the same permutation test was performed on the $\gamma$ level with the $\alpha$ value set to 0.05 . As proposed by Thébaud et al. (2005), the proportion of simulations within a single block resulting in the rejection of a false null hypothesis was used as an estimate of power. Similarly, the estimate of type I error was calculated as the proportion of simulations in which PT rejected the null hypothesis when it was true. The estimates of power and type I error were averaged to be compared among tests, sample sizes, and windows sizes. The above estimates were also correlated with the Spearman $\rho$ correlation coefficient to $m$ (i.e., testing $\rho(m)$ ) and to

$$
\left(\begin{array}{c}
n \\
m
\end{array}\right)\left(\text { i.e., testing } \rho\left(\begin{array}{l}
n \\
m
\end{array}\right)\right)
$$

with a $P$ value cut-off set to 0.05 .

An example to check the influence of the spatial pattern of the points in the set $T$ on power and type I error of PT was included. Three DGPs consisting in a clustered (PPC), a random (PPR) and a dispersed (PPD) point process including $n=20$ points were designed in a squared $1 \times 1$ units window. PPC was realized in eight variants by randomly drawing the $x$ and $y$ coordinates of the points from beta functions with shape parameters $a=b$ set to 2 (PPC2), 4 (PPC4), 8 (PPC8), 16 (PPC16), 32 (PPC32), 64 (PPC64), 128 (PPC128), and 256 (PPC256). PPR was designed in a single variant as a Poisson process for complete spatial randomness (CSR). PPD was obtained in eight variants through a Strauss process (Strauss 1975) with the parameter R set to 0.1 and the parameter gamma set to 0 (PPD0), 0.125 (PPD125), 0.250 (PPD250), 0.375 (PPD375), 0.500 (PPD500), 0.625 (PPD625), 0.750 (PPD750), and 0.875 (PPD875). The level $\gamma$ was assigned to $m=4$ points of the subset $I$ through clustering $(\mathrm{C})$, randomization (R), and dispersion (D). C was designed by randomly selecting two first-order nearest neighbor points to two nearest neighboring ones, $\mathrm{R}$ by drawing four points with the extraction probability set constant for each of the 20 points and D by identifying one firstorder nearest neighbor to each corner or the window. For every point process variant and $\gamma$ assignment, each PT was iteratively performed for $10^{4}$ times resulting in $1.53 \times 10^{6} \mathrm{MC}$ simulations (17 point process variants $\times 3 \gamma$ assignment $\times 3$ tests $\times 10^{4}$ simulations). Simulations whose PPC, PPR, and PPD were not confirmed as respectively clustered, random, or dispersed according to the Clark and Evans test at 0.05 significance level cutoff were discarded and rerun until test confirmation. Power and type I error were assessed as described above for each $10^{4}$ simulation and averaged within tests for both $T$ and $I$ points spatial patterns.

Biological validation. The RT were validated on data gathered from Gonthier et al. (2012). In this study, 44 sampling points equipped with spores trapping devices were located within a 3,030 ha forest in the Circeo National Park, in central Italy. Spore trapping devices allowed to determine the spores deposition rate (DR), expressed as the number of viable spores per square meter per hour (spores $\mathrm{m}^{-2} \mathrm{~h}^{-1}$ ), of two fungal pathogens causing root rot on conifers. The first pathogen, Heterobasidion annosum, is native in the area, while the second one, $H$. irregulare, is an alien invasive species. Geostatistical analyses of spatial autocorrelation (i.e., global Moran's I test and general G-statistic) performed on the DR showed that $H$. irregulare was ubiquitous and distributed in the area according to a random spatial pattern, while $H$. annosum showed significant clustering around patches of conifers.

To validate the RT, the set $T$ was defined including all $n=44$ sampling points. Two categorical variables $\Gamma_{1}$ (i.e., "presence of $H$. annosum spores") and $\Gamma_{2}$ (i.e., "presence of $H$. irregulare spores") were defined. For $\Gamma_{1}$, the $\gamma_{1}$ level (i.e., "H. annosum spores

TABLE 2. Data generating processes (DGPs) verifying or not verifying the null hypothesis $H_{0}$ of each test included in mean distance permutation tests (PT) and combinations of the three DGPs used to perform the blocks of Monte Carlo simulations for power and type I error estimation

\begin{tabular}{lcccc}
\hline Test & DGP verifying $H_{0}$ & DGP not verifying $H_{0}$ & $\begin{array}{c}\text { Number of simulations per DGP to } \\
\text { estimate power within each block }\end{array}$ & $\begin{array}{c}\text { Number of simulations per DGP to estimate } \\
\text { type I error within each block }\end{array}$ \\
\hline $\mathrm{P}_{2 \mathrm{~T}}$ & $\mathrm{PP} 1$ & $\mathrm{PP} 2 ; \mathrm{PP} 3$ & $5 \times 10^{3} \mathrm{PP} 2+5 \times 10^{3} \mathrm{PP}$ & $1 \times 10^{4} \mathrm{PP} 1$ \\
$\mathrm{P}_{\mathrm{LT}}$ & $\mathrm{PP}$; PP3 & $\mathrm{PP} 2$ & $1 \times 10^{4} \mathrm{PP} 2$ & $5 \times 10^{3} \mathrm{PP1}+5 \times 10^{3} \mathrm{PP} 3$ \\
$\mathrm{P}_{\mathrm{RT}}$ & $\mathrm{PP}$; PP2 & $\mathrm{PP} 3$ & $1 \times 10^{4} \mathrm{PP} 3$ & $5 \times 10^{3} \mathrm{PP} 1+5 \times 10^{3} \mathrm{PP} 2$ \\
\hline
\end{tabular}


are present") was assigned to the $m_{1}$ sampling points with $H$. annosum DR $>0$, which were included in the subset $I_{1}$. Similarly, the $\gamma_{2}$ level (i.e., " $H$. irregulare spores are present") was assigned to the $m_{2}$ sampling points with $H$. irregulare DR $>0$ to define the subset $I_{2} . \mathrm{R}_{2 \mathrm{~T}}, \mathrm{R}_{\mathrm{LT}}$, and $\mathrm{R}_{\mathrm{RT}}$ with $\alpha=0.05, B=10^{4}$, and $\lambda=0.95$ were performed on both $\gamma_{1}$ and $\gamma_{2}$ levels.

Application to a case study. An application of the MDT to a case study was carried out to test the relation between the plantation density and the incidence of Gnomoniopsis castanea, an emerging fungal pathogen causing the nut rot of chestnut (Visentin et al. 2012). During October 2013, the coordinates of 203 sweet chestnuts (Castanea sativa) were recorded in UTM WGS84 zone $32 \mathrm{~N}$ system (m) with a GPS device (Magellan Mobile Mapper 6, Magellan Navigation Inc., Santa Clara, CA). The trees grew in the sweet chestnut orchard Vivaio Gambarello, set in the north-west of Italy (E 394,925; N 4,906,885). An NNHC analysis (Mitchell 2009) was performed on CrimeStat 3.3. (Ned Levine \& Associates, Houston, TX) with $2 \times 10^{3}$ iterations and significance level cut-off set to 0.05 . The two clusters of sweet chestnuts including the largest number of trees (areas $\mathrm{C} 1$ and $\mathrm{C} 2$, see results) were selected and two not clustering groups (areas NC1 and NC2) with the same number of sweet chestnuts were randomly chosen. The mean value of the triangular Euclidean distance matrix among all the sweet chestnuts was calculated for areas $\mathrm{C} 1, \mathrm{C} 2, \mathrm{NC} 1$, and NC2. Up to 40 nuts per tree were collected from the crown of each sweet chestnut in the above mentioned areas. Fragments of the nuts kernel were plated in Petri dishes on malt extract agar (MEA) to assess the presence/absence of $G$. castanea in the fruit tissues at the tree level. Isolations and fungal identification were performed as described by Lione et al. (2015). The incidence of $G$. castanea was calculated as the ratio, in percent, between the $m_{C 1}, m_{C 2}$, $m_{N C 1}$, and $m_{N C 2}$ trees carrying at least one infected nut (i.e., subsets $I_{C 1}, I_{C 2}, I_{N C 1}$, and $I_{N C 2}$ of areas $\mathrm{C} 1, \mathrm{C} 2, \mathrm{NC} 1$, and $\mathrm{NC2}$ ) and the $n_{C 1}, n_{C 2}, n_{N C 1}$, and $n_{N C 2}$ trees growing in each area (i.e., sets $T_{C 1}, T_{C 2}, T_{N C 1}$, and $T_{N C 2}$ ). The categorical variable $\Gamma$ (i.e., "presence of G. castanea in at least one nut") was defined and the level $\gamma$ (i.e., "G. castanea is present in at least one nut") was assigned to the $m_{C 1}, m_{C 2}, m_{N C 1}$, and $m_{N C 2}$ trees. The incidence of the pathogen was compared among the four above mentioned areas with a $\chi^{2}$ test performed with a significance cut-off of 0.05 . For each area, $\bar{d}_{0}$ and

$$
\left(\begin{array}{c}
n \\
m
\end{array}\right)
$$

were calculated. $\mathrm{P}_{2 \mathrm{~T}}, \mathrm{P}_{\mathrm{LT}}$, and $\mathrm{P}_{\mathrm{RT}}$ with $\alpha=0.05$ and $\mathrm{R}_{2 \mathrm{~T}}, \mathrm{R}_{\mathrm{LT}}$, and $\mathrm{R}_{\mathrm{RT}}$ with $\alpha=0.05, B=B_{\text {min }}, B=5 \times 10^{2}$ and $\lambda=0.95$ were performed on the $\gamma$ level for every area. The $B_{\min }$ parameter is the estimate of the minimum number of $B$ satisfying the nonambiguity condition $\alpha<L_{p r} \mathrm{~V} \alpha>U_{p r}$. $B_{\text {min }}$ was assessed through MC simulations consisting in 100 runs per randomization tests per area. Each run was performed iterating the RT by increasing $B$ of 1 unit from 1 to 850 . For every run the $B_{\text {nac }}$ value was defined as the minimum $B$ value satisfying the nonambiguity condition. $B_{\min }$ was assessed by selecting the highest $B_{\text {nac }}$ value. A total of $1.02 \times 10^{6} \mathrm{MC}$ simulations were performed ( 3 tests $\times 850 B$ values $\times 100$ run $\times 4$ areas).

\section{RESULTS}

Software design. MDT algorithms are provided as scripts to run in R environment (Supplementary File S1). The algorithms have also been embedded in the MDT software, a "point-and-click" graphic user interface (GUI) running on the internet browser. The user is supposed to provide the input data as a spreadsheet .csv file with as many rows as the points in the set $T$, two columns for the spatial coordinates, one column for the $\Gamma$ variable. Cells included in this last column indicate for all points the assigned levels of $\Gamma$. The other inputs required (Table 1) should be specified directly in the GUI. The MDT software, its user manual, and the installation instructions are freely available from Supplementary File S2.

MC estimates of PT power and type I error. On average, the estimates of power of PT ranged from 0.8884 to 0.9917 with $n=$ 15 and from 0.9493 to 0.9937 with $n=20$, while the estimates of type I error were comprised between 0.0247 and $0.0496(n=15)$ and between 0.0245 and $0.0493(n=20)$ depending on the test. The maximum average power was attained by $\mathrm{P}_{\mathrm{LT}}$, followed by $\mathrm{P}_{2 \mathrm{~T}}$ and $\mathrm{P}_{\mathrm{RT}}$. Comparing $n=15$ with $n=20$, the average power of all tests raised between 0.0020 and 0.0615 . The minimum values of type I error were observed in $\mathrm{P}_{\mathrm{LT}}$ and $\mathrm{P}_{\mathrm{RT}}$, followed by $\mathrm{P}_{2 \mathrm{~T}}$. Within the same test, the window size affected the average values of the power and of the type I error estimates resulting in a maximum absolute difference of \pm 0.007 . Significant correlations $(P<0.05)$ were detected between the power estimates and $m$ in $\mathrm{P}_{\mathrm{LT}}$, regardless of the window size for $n=15$ and in the $6 \times 6$ units window for $n=20$. Significant values of

$$
\rho\left(\begin{array}{l}
n \\
m
\end{array}\right)
$$

were observed in $\mathrm{P}_{2 \mathrm{~T}}$ and $\mathrm{P}_{\mathrm{RT}}$ for both windows sizes with

$$
n=15\left(\rho\left(\begin{array}{c}
n \\
m
\end{array}\right)>0.8621 ; P<0.05\right)
$$

and in all tests except $\mathrm{P}_{\mathrm{LT}}$ in the $4 \times 4$ units window with

$$
n=20\left(\rho\left(\begin{array}{c}
n \\
m
\end{array}\right)>0.8668 ; P<0.05\right)
$$

No significant correlations $(P>0.05)$ were observed between the estimates of type I error and $m$, with the exception of $\mathrm{P}_{\mathrm{LT}}$ in the $4 \times 4$ units window for $n=20$. Significant correlations $(P<0.05)$ were detected between the estimates of type I error and

$$
\left(\begin{array}{c}
n \\
m
\end{array}\right)
$$

in $\mathrm{P}_{\mathrm{RT}}(6 \times 6$ units window, $n=15)$, in $\mathrm{P}_{2 \mathrm{~T}}$ (both windows, $\left.n=20\right)$, and in $\mathrm{P}_{\mathrm{LT}}(6 \times 6$ units window, $n=20)$ (Table 3 for $n=15$, Table 4 for $n=20$ ).

In the example to check the influence of the spatial pattern of the points of the set $T$ on power and type I error, the PT attained on average a power ranging from 0.9757 to 0.9989 for PPC, from 0.9771 to 0.9990 for PPR, and from 0.9934 to 0.9999 for PPD. The average type I error was comprised between 0.0250 and 0.0504 for PPC, between 0.0250 and 0.0519 for PPR, and between 0.0246 and 0.0494 for PPD, with the largest values observed in $\mathrm{P}_{2 \mathrm{~T}}$. The average power calculated regardless of the point process generating $T$ ranged from 0.9912 to 0.9770 for $\mathrm{P}_{2 \mathrm{~T}}$ and attained the values of 0.9916 for $\mathrm{P}_{\mathrm{LT}}$ and 0.9993 for $\mathrm{P}_{\mathrm{RT}}$. The average type I error was 0.0500 for $\mathrm{P}_{2 \mathrm{~T}}$ and was comprised between 0 and 0.0498 for $\mathrm{P}_{\mathrm{LT}}$ and from 0 to 0.0499 for $\mathrm{P}_{\mathrm{RT}}$ (Table 5).

Biological validation. For the variable $\Gamma_{1}$, the level $\gamma_{1}$ was assigned to $m_{1}=16$ sampling points that fulfilled the condition H. annosum DR $>0$, defining the subset $I_{1}$ (Fig. 1A). For $\gamma_{1}$, the value of $\bar{d}_{0}$ attained $2,767 \mathrm{~m}$, while $\bar{D}$ was $3,449 \mathrm{~m}$ in $\mathrm{R}_{2 \mathrm{~T}}$ and $3,443 \mathrm{~m}$ in both $\mathrm{R}_{\mathrm{LT}}$ and $\mathrm{R}_{\mathrm{RT}}$. Based on $\mathrm{R}_{2 \mathrm{~T}}$, sampling points where spores of $H$. annosum had been detected were not randomly distributed within the sampling points $\left(p_{r}=0.0122, L_{p r}=0.0117\right.$, $\left.U_{p r}=0.0158\right) . \mathrm{R}_{\mathrm{LT}}$ indicated a clustered spatial pattern of the points with $H$. annosum $\mathrm{DR}>0$ within the sampling points $\left(p_{r}=0.0092\right.$, $\left.L_{p r}=0.0065, U_{p r}=0.0113\right)$. Finally, $\mathrm{R}_{\mathrm{RT}}$ was not significant, showing a not dispersed spatial distribution of the points 
with $H$. annosum DR $>0$ within the sampling points $\left(p_{r}=0.9892\right.$, $\left.L_{p r}=0.9875, U_{p r}=0.9918\right)$. The subset $I_{2}$ was defined by assigning the level $\gamma_{2}$ of the variable $\Gamma_{2}$ to the $m_{2}=29$ points that satisfied the condition $H$. irregulare DR $>0$ (Fig. 1B). In this case, $\bar{d}_{0}$ attained a value of $3,281 \mathrm{~m}$, while $\bar{D}$ ranged from $3,445 \mathrm{~m}$ in $\mathrm{R}_{\mathrm{LT}}$ to $3,446 \mathrm{~m}$ in $\mathrm{R}_{2 \mathrm{~T}}$ and $\mathrm{R}_{\mathrm{RT}}$. $\mathrm{R}_{2 \mathrm{~T}}$ output indicated that sampling points where spores of $H$. irregulare had been identified were randomly distributed within the sampling points $\left(p_{r}=0.2554, L_{p r}=0.2422, U_{p r}=\right.$ 0.2699 ). According to $\mathrm{R}_{\mathrm{LT}}$, points with $H$. irregulare $\mathrm{DR}>0$ were not clustered within the sampling points $\left(p_{r}=0.1278, L_{p r}=0.1272\right.$, $\left.U_{p r}=0.1402\right)$, while the $\mathrm{R}_{\mathrm{RT}}$ showed a not dispersed spatial pattern for the same points $\left(p_{r}=0.8739, L_{p r}=0.8636, U_{p r}=\right.$ 0.8781 ). In all RT performed, the condition $L_{p r} \leq \alpha \leq U_{p r}$ was not verified for $B=10^{4}$.

Application to the case study. The NNHC showed the presence of 24 first order clusters, comprising two to five trees, and two second order clusters (areas C1 and C2), composed of four and five first order clusters with a total of $n_{C 1}=14$ and $n_{C 2}=17$ sweet chestnuts, respectively $(P<0.05)$ (Fig. 2A and B). The same number of trees was used to define the areas NC1 $\left(n_{N C l}=14\right)$ and $\mathrm{NC} 2\left(n_{N C 2}=17\right)$ (Fig. $2 \mathrm{C}$ and D). The mean value of the triangular Euclidean distance matrix among all trees attained $12.8 \mathrm{~m}$ in $\mathrm{C} 1$, $9.9 \mathrm{~m}$ in $\mathrm{C} 2,13.1 \mathrm{~m}$ in $\mathrm{NC} 1$, and $26.3 \mathrm{~m}$ in NC2. The level $\gamma$ was assigned to the $m_{C 1}=10, m_{C 2}=9, m_{N C 1}=8$, and $m_{N C 2}=11$ sweet chestnuts carrying at least one nut infected by G. castanea (Fig. 2). The incidence of G. castanea was $71.4 \%$ in $\mathrm{C} 1,52.9 \%$ in $\mathrm{C} 2,57.1 \%$ in $\mathrm{NC} 1$, and $64.7 \%$ in $\mathrm{NC} 2$. The $\chi^{2}$ test indicated no significant differences among the incidence level of the four areas $(P=0.7312)$. The $\bar{d}_{0}$ distance ranged from 18.8 to $32.7 \mathrm{~m}$, with the lowest values observed in $\mathrm{C} 1$ and $\mathrm{C} 2$, while

$$
\left(\begin{array}{c}
n \\
m
\end{array}\right)
$$

was comprised between 1,001 and 24,310, depending on the area. The MDT performed were never significant $\left(p_{e}>0.05 ; p_{r}>0.05\right)$, regardless of the area, indicating a random ${ }_{2 \mathrm{~T}}$ ), not clustered ( ${ }_{\mathrm{LT}}$ ) and not dispersed ( ${ }_{\mathrm{RT}}$ ) spatial distribution of sweet chestnuts infected by $G$. castanea within the sampled trees. The $B_{\min }$ values ranged from 4 to 493 depending on the test and on the area. For all areas $B=5 \times 10^{2}$ was adequate to perform the RT since the value was larger than $B_{\min }$ and the condition $L_{p r} \leq \alpha \leq U_{p r}$ was not verified. Increasing $B$ values reduced the width of the interval $\left(L_{p r}, U_{p r}\right)$ for every RT in all areas (Table 6).

\section{DISCUSSION}

The analysis of the spatial pattern of plant diseases is a pivotal issue in plant pathology since it is aimed at gathering relevant information about biological, epidemiological and ecological aspects of pathogens. The main goal of our study was to propose the MDT as a series of geostatistical tests to assess the spatial pattern of plant diseases when the variable of phytopathological interest is categorical and to provide the user with an intuitive "point-andclick" software to perform the tests.

The MDT are based on resampling methods (i.e., permutation and randomization) that can be profitably employed when they are assumed to mimic the stochastic process underlying the phenomenon under investigation (Carsey and Harden 2014). This may often be the case in plant pathology, which is mostly focused on the

TABLE 3. Estimates of power and type I error for the mean distance permutation tests (PT) obtained through Monte Carlo simulations and results of the correlation analysis for $n=15^{\text {a }}$

\begin{tabular}{|c|c|c|c|c|c|c|c|c|c|c|c|c|c|}
\hline \multirow[b]{3}{*}{$m$} & \multirow[b]{3}{*}{$\left(\begin{array}{c}n \\
m\end{array}\right)$} & \multicolumn{4}{|c|}{$\mathrm{P}_{2 \mathrm{~T}}$} & \multicolumn{4}{|c|}{$\mathrm{P}_{\mathrm{LT}}$} & \multicolumn{4}{|c|}{$\mathrm{P}_{\mathrm{RT}}$} \\
\hline & & \multicolumn{2}{|c|}{$\begin{array}{l}6 \times 6 \text { units } \\
\text { window }\end{array}$} & \multicolumn{2}{|c|}{$\begin{array}{l}4 \times 4 \text { units } \\
\text { window }\end{array}$} & \multicolumn{2}{|c|}{$\begin{array}{c}6 \times 6 \text { units } \\
\text { window }\end{array}$} & \multicolumn{2}{|c|}{$\begin{array}{l}4 \times 4 \text { units } \\
\text { window }\end{array}$} & \multicolumn{2}{|c|}{$\begin{array}{c}6 \times 6 \text { units } \\
\text { window }\end{array}$} & \multicolumn{2}{|c|}{$\begin{array}{l}4 \times 4 \text { units } \\
\text { window }\end{array}$} \\
\hline & & Power & $\begin{array}{c}\text { Type I } \\
\text { error }\end{array}$ & Power & $\begin{array}{c}\text { Type I } \\
\text { error }\end{array}$ & Power & $\begin{array}{c}\text { Type I } \\
\text { error }\end{array}$ & Power & $\begin{array}{l}\text { Type I } \\
\text { error }\end{array}$ & Power & $\begin{array}{l}\text { Type I } \\
\text { error }\end{array}$ & Power & $\begin{array}{l}\text { Type I } \\
\text { error }\end{array}$ \\
\hline 2 & 105 & 0.7638 & 0.0499 & 0.7675 & 0.0419 & 0.8983 & 0.0264 & 0.9006 & 0.0246 & 0.6528 & 0.0237 & 0.6503 & 0.0239 \\
\hline 3 & 455 & 0.8768 & 0.0491 & 0.8744 & 0.0496 & 0.9998 & 0.0241 & 0.9997 & 0.0256 & 0.7476 & 0.0229 & 0.7470 & 0.0240 \\
\hline 4 & 1,365 & 0.9312 & 0.0499 & 0.9275 & 0.0471 & 1.0000 & 0.0232 & 1.0000 & 0.0250 & 0.8844 & 0.0251 & 0.8814 & 0.0239 \\
\hline 7 & 6,435 & 0.9513 & 0.0484 & 0.9526 & 0.0458 & 1.0000 & 0.0245 & 1.0000 & 0.0256 & 0.9562 & 0.0248 & 0.9566 & 0.0248 \\
\hline 8 & 6,435 & 0.9569 & 0.0517 & 0.9537 & 0.0504 & 1.0000 & 0.0259 & 1.0000 & 0.0244 & 0.9619 & 0.0266 & 0.9654 & 0.0254 \\
\hline 9 & 5,005 & 0.9561 & 0.0473 & 0.9567 & 0.0516 & 1.0000 & 0.0247 & 1.0000 & 0.0250 & 0.9594 & 0.0247 & 0.9633 & 0.0235 \\
\hline 10 & 3,003 & 0.9482 & 0.0471 & 0.9517 & 0.0482 & 1.0000 & 0.0260 & 1.0000 & 0.0247 & 0.9532 & 0.0261 & 0.9491 & 0.0248 \\
\hline 11 & 1,365 & 0.9387 & 0.0484 & 0.9367 & 0.0487 & 1.0000 & 0.0242 & 1.0000 & 0.0225 & 0.9345 & 0.0255 & 0.9355 & 0.0257 \\
\hline 12 & 455 & 0.9040 & 0.0488 & 0.9036 & 0.0511 & 1.0000 & 0.0259 & 1.0000 & 0.0250 & 0.9171 & 0.0245 & 0.9160 & 0.0254 \\
\hline 13 & 105 & 0.8262 & 0.0531 & 0.8267 & 0.0495 & 1.0000 & 0.0257 & 1.0000 & 0.0231 & 0.8530 & 0.0245 & 0.8588 & 0.0235 \\
\hline$\rho($ & $P$ value & 0.0001 & 0.4358 & 0.0001 & 0.3987 & 0.0747 & 0.5221 & 0.0747 & 0.2489 & 0.0001 & 0.0163 & 0.0003 & 0.1806 \\
\hline
\end{tabular}

a The estimates are provided for each block of simulations ranked according to the $m$ values and divided for two-tailed, left-tailed, and right-tailed tests $\left(\mathrm{P}_{2 \mathrm{~T}}, \mathrm{P}_{\mathrm{RT}}\right.$, and $\mathrm{P}_{\mathrm{LT}}$ ) and window size. The number of combinations

$$
\left(\begin{array}{c}
n \\
m
\end{array}\right)
$$

enumerated for each value of $m$ is listed. The average of power and type I error as well as the Spearman correlation coefficient between the estimates and

$$
m[\text { i.e., } \rho(m)] \text { and }\left(\begin{array}{c}
n \\
m
\end{array}\right)\left[\text { i.e., } \rho\left(\begin{array}{c}
n \\
m
\end{array}\right)\right]
$$

are reported with the related $P$ value for all tests and window sizes. The symbol $*$ indicates correlation coefficients significant at 0.05 cut-off. 
dynamics of the disease rather than on the factors underlying the actual distribution of the plants within the study area. In a regular plantation the location of the plants is the result of a predetermined design, while the occurrence of the pathogen may be realistically assumed as a stochastic event, which could have resulted in a different outcome depending on the random factors influencing the disease (e.g., environmental variables, inoculum pressure). In natural and seminatural ecosystems a certain level of stochasticity is intrinsic in the distribution of plants, yet it may often be considered negligible in relation to the stochasticity involved in the epidemiological processes. For the above cited reasons, the MDT permute (i.e., PT) or randomize (i.e., RT) the assignment of the level $\gamma$ of the categorical variable $\Gamma$ to $m$ out of $n$ points, while keeping constant the coordinates of the $n$ points. Consequently, the MDT approach implies stochasticity in the distribution of $\gamma$ within a network of points with fixed location, assuming that randomness occurs when each point is equally likely to be included in the subset $I$ regardless of the inclusion of any other point (Mitchell 2009). MDT differentiate from other common methods for the analysis of point patterns such as the Clark and Evans test, the F-function, the G-function, the Ripley's Kfunction, and the L-function. In fact, these methods assume that the whole set of points under investigation is a realization of a stochastic point process within a fixed and bounded region. The spatial pattern of the points is assessed by calculating a specific parameter whose null distribution is approximated by a Gaussian curve, or derived from MC simulations based on a Poisson process for CSR (Clark and Evans 1954; Crawley 2013; Mitchell 2009; Szmyt 2014). While a point process within a fixed window can lead to an infinite number of distinct realizations, the definition of a subset of points within a fixed set of points can generate only a finite number of outcomes. For this reason the MDT algorithms are largely based on the estimation of the PMF of the distance parameter $\bar{d}$ through either permutation or randomization. Both PT and RT were designed in the two-tailed, left-tailed, and right-tailed versions. The user's preference for the one-tailed tests might derive either from the spatial pattern qualitatively observed, or from some biologically relevant information related to the epidemiology and infection biology of the pathogen. Separate algorithms were provided depending on the tails of the PMF, because the extension of the asymptotic approach to switch from the one-tailed $P$ value to the two-tailed one is not recommended (Hartwig 2013).

Permutation and randomization are currently considered robust and flexible standards for the assessment of the PMF of parameters whose asymptotic distribution is unknown, numerically intractable, or poorly performing with realistic sample sizes. Moreover, the permutation approach is often advocated since it allows to obtain reliable outcomes without relying on constraining assumptions, which might not be verified, and its performances are generally comparable to the parametric counterpart, or even superior (Carsey and Harden 2014; Ernst 2004; Good 2000; Peres-Neto and Olden

TABLE 4. Estimates of power and type I error for the mean distance permutation tests (PT) obtained through Monte Carlo simulations and results of the correlation analysis for $n=20^{\mathrm{a}}$



a The estimates are provided for each block of simulations ranked according to the $m$ values and divided for two-tailed, left-tailed, and right-tailed tests $\left(\mathrm{P}_{2 \mathrm{~T}}, \mathrm{P}_{\mathrm{RT}}\right.$, and $\mathrm{P}_{\mathrm{LT}}$ ) and window size. The number of combinations

$$
\left(\begin{array}{c}
n \\
m
\end{array}\right)
$$

enumerated for each value of $m$ is listed. The average of power and type I error as well as the Spearman correlation coefficient between the estimates and

$$
m[\text { i.e., } \rho(m)] \text { and }\left(\begin{array}{c}
n \\
m
\end{array}\right)\left[\text { i.e., } \rho\left(\begin{array}{c}
n \\
m
\end{array}\right)\right]
$$


2001; Wigginton et al. 2005). However, depending on the available computational power, permutation methods may pose heavy issues in terms of time consumption and technical feasibility (Ernst 2004). In such a case, the switch to randomization is recommended, provided that the number of random combinations selected is large enough to achieve reliable approximations of the permutation outcome (Carsey and Harden 2014; Ernst 2004). In the RT this number (i.e., $B$ ) is adequate if the corresponding confidence interval of $p_{r}$ excludes the cut-off level $\alpha$, since otherwise the null hypothesis would be undecidable (Ernst 2004). In agreement with the resampling theory (Ernst 2004), the MC simulations carried out for the case study of $G$. castanea showed that increasing $B_{\text {min }}$ values were needed with $p_{e}$ approaching $\alpha$. Besides the reduction of the 95\% confidence interval width of $p_{r}$, as well as the trend to the


different point processes generating the set $T$ and spatial patterns of the subset $I^{\mathrm{a}}$

\begin{tabular}{|c|c|c|c|c|c|c|c|c|c|c|c|c|c|c|c|}
\hline \multirow[b]{3}{*}{$T$ set point process } & \multicolumn{9}{|c|}{$I$ subset spatial pattern } & & & & & & \\
\hline & \multicolumn{3}{|c|}{$\mathrm{C}$} & \multicolumn{3}{|c|}{$\mathrm{R}$} & \multicolumn{3}{|c|}{$\mathrm{D}$} & \multicolumn{3}{|c|}{ Average power } & \multicolumn{3}{|c|}{ Average type I error } \\
\hline & $\mathrm{P}_{2 \mathrm{~T}}$ & $\mathrm{P}_{\mathrm{LT}}$ & $\mathrm{P}_{\mathrm{RT}}$ & $\mathrm{P}_{2 \mathrm{~T}}$ & $\mathrm{P}_{\mathrm{LT}}$ & $\mathrm{P}_{\mathrm{RT}}$ & $\mathrm{P}_{2 \mathrm{~T}}$ & $\mathrm{P}_{\mathrm{LT}}$ & $\mathrm{P}_{\mathrm{RT}}$ & $\mathrm{P}_{2 \mathrm{~T}}$ & $\mathrm{P}_{\mathrm{LT}}$ & $\mathrm{P}_{\mathrm{RT}}$ & $\mathrm{P}_{2 \mathrm{~T}}$ & $\mathrm{P}_{\mathrm{LT}}$ & $\mathrm{P}_{\mathrm{RT}}$ \\
\hline PPC256 & 0.9598 & 0.9877 & 0.0000 & 0.0490 & 0.0491 & 0.0505 & 0.9989 & 0.0000 & 1.0000 & 0.9757 & 0.9877 & 0.9989 & 0.0504 & 0.0252 & 0.0250 \\
\hline PPC128 & 0.9594 & 0.9880 & 0.0000 & 0.0496 & 0.0479 & 0.0510 & 0.9988 & 0.0000 & 1.0000 & & & & & & \\
\hline PPC64 & 0.9611 & 0.9879 & 0.0000 & 0.0481 & 0.0500 & 0.0500 & 0.9981 & 0.0000 & 1.0000 & & & & & & \\
\hline PPC32 & 0.9607 & 0.9887 & 0.0000 & 0.0497 & 0.0508 & 0.0501 & 0.9980 & 0.0000 & 0.9999 & & & & & & \\
\hline PPC16 & 0.9660 & 0.9893 & 0.0000 & 0.0516 & 0.0514 & 0.0512 & 0.9954 & 0.0000 & 0.9999 & & & & & & \\
\hline PPC8 & 0.9680 & 0.9885 & 0.0000 & 0.0493 & 0.0508 & 0.0501 & 0.9911 & 0.0000 & 0.9989 & & & & & & \\
\hline PPC4 & 0.9685 & 0.9884 & 0.0000 & 0.0502 & 0.0495 & 0.0509 & 0.9778 & 0.0000 & 0.9975 & & & & & & \\
\hline PPC2 & 0.9637 & 0.9832 & 0.0000 & 0.0558 & 0.0530 & 0.0466 & 0.9456 & 0.0000 & 0.9951 & & & & & & \\
\hline PPR & 0.9808 & 0.9898 & 0.0000 & 0.0519 & 0.0507 & 0.0499 & 0.9734 & 0.0000 & 0.9990 & 0.9771 & 0.9898 & 0.9990 & 0.0519 & 0.0253 & 0.0250 \\
\hline PPD875 & 0.9880 & 0.9944 & 0.0000 & 0.0493 & 0.0509 & 0.0511 & 0.9966 & 0.0000 & 1.0000 & 0.9934 & 0.9958 & 0.9999 & 0.0494 & 0.0246 & 0.0249 \\
\hline PPD750 & 0.9869 & 0.9938 & 0.0000 & 0.0508 & 0.0495 & 0.0502 & 0.9958 & 0.0000 & 0.9995 & & & & & & \\
\hline PPD625 & 0.9934 & 0.9977 & 0.0000 & 0.0476 & 0.0488 & 0.0457 & 0.9975 & 0.0000 & 0.9997 & & & & & & \\
\hline PPD500 & 0.9905 & 0.9963 & 0.0000 & 0.0493 & 0.0485 & 0.0466 & 0.9969 & 0.0000 & 0.9999 & & & & & & \\
\hline PPD375 & 0.9914 & 0.9961 & 0.0000 & 0.0493 & 0.0488 & 0.0532 & 0.9962 & 0.0000 & 1.0000 & & & & & & \\
\hline PPD250 & 0.9923 & 0.9965 & 0.0000 & 0.0494 & 0.0480 & 0.0521 & 0.9969 & 0.0000 & 0.9999 & & & & & & \\
\hline PPD125 & 0.9899 & 0.9959 & 0.0000 & 0.0499 & 0.0493 & 0.0499 & 0.9969 & 0.0000 & 0.9999 & & & & & & \\
\hline PPD0 & 0.9889 & 0.9954 & 0.0000 & 0.0493 & 0.0498 & 0.0498 & 0.9968 & 0.0000 & 0.9999 & & & & & & \\
\hline Average & 0.9770 & 0.9916 & 0.0000 & 0.0500 & 0.0498 & 0.0499 & 0.9912 & 0.0000 & 0.9993 & & & & & & \\
\hline Rejected tests & $\mathrm{p}$ & $\mathrm{p}$ & $\mathrm{e}$ & $\mathrm{e}$ & $\mathrm{e}$ & $\mathrm{e}$ & $\mathrm{p}$ & $\mathrm{e}$ & $\mathrm{p}$ & & & & & & \\
\hline
\end{tabular}

a The rows from PPC256 to PPD0 show the proportion of tests rejecting the null hypothesis according to the variants of clustered (PPC), random (PPR), and dispersed (PPD) point processes generating $T$, as well as the average power and the average type I error achieved by each test within the same point process. The codes next to the point processes refer to their variants (i.e., parameters setting), as described in the Materials and Methods. The columns refer to the proportion of tests rejected by each PT for clustering $(\mathrm{C})$, randomization $(\mathrm{R})$, and dispersion $(D)$ of the $m$ points of the subset $I$. The last row (average) shows the mean values of the columns regardless of the spatial pattern of $T$, specifying if the mean represents power (p) or type I error (e) of the test.

A

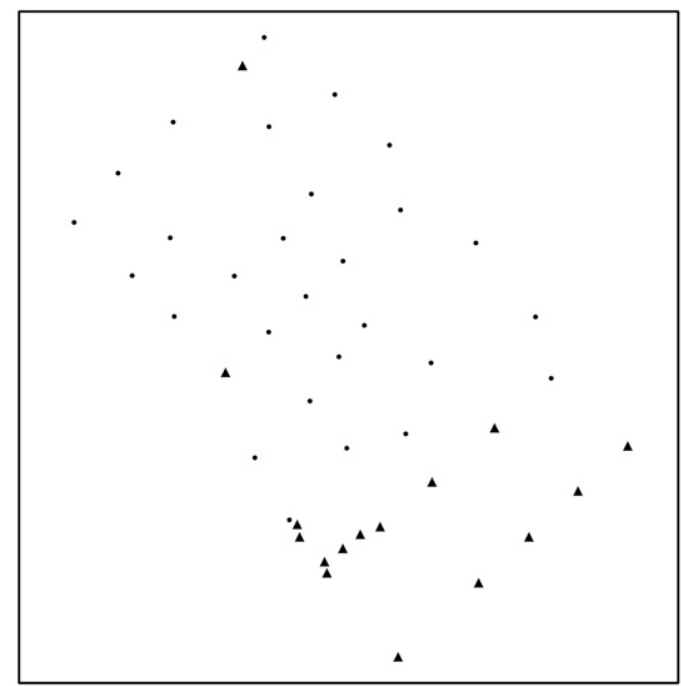

- spores of $H$. annosum are present (subset $I_{1}$ )

- spores of $H$. annosum are absent
B


Fig. 1. Maps of the sampling points in the Circeo National Park that displayed the presence of spores of A, Heterobasidion annosum and $\mathbf{B}, H$. irregulare, defining the subsets $I_{1}$ and $I_{2}$, respectively. 
convergence of the randomization results to the permutation ones could be observed empirically switching from $B_{\min }$ to $5 \times 10^{2}$. Regardless of the $B_{\text {min }}$, in the practice low $B$ values ( $<20$ for $\alpha=0.05$ and $<100$ for $\alpha=0.01$ ) are not recommendable (Carsey and Harden 2014; Micciolo et al. 2013).

The null hypotheses were formulated according to the general principles underlying the permutation and randomization approach (Carsey and Harden 2014; Hartwig 2013) using the statistic $\bar{d}$ as overall index of the distances that separate a set of points in a plane. The comparison among different distance indexes was not a goal of this study, yet the statistic $\bar{d}$ is only one among the distance measures that could have been calculated. For instance, the Clark and Evans test, the F-function, and the G-function are based on the mean of the first-order nearest neighbor distances, while the Ripley's K-function and the L-function rely on weighted distances among all features (Clark and Evans 1954; Mitchell 2009; Szmyt 2014). Even though not one of the distance indexes can perfectly discriminate between random and not random spatial pattern, the definition of $\bar{d}$ is consistent with the assumptions about the spatial differences among clustered, randomized, and dispersed point patterns (Crawley 2013; Mitchell 2009) and it is included in standard statistical methods dealing with clustering problems (Aldenderfer and Blashfield 1987). It is worth noting that the case study of $G$. castanea showed that the values achieved by $\bar{d}$ for all trees growing in each clustering area were lower than the values observed in nonclustering areas, despite the NNHC performed for cluster identification was based on another distance index (Mitchell 2009).

Unlike F-, G-, K-, and L-functions, the MDT do not account for scale dependency of the spatial pattern, but the MDT approach could be applied at both global and local scale since the definition of $T$ is arbitrary (Mitchell 2009).

The assessment of power and type I error of permutation tests requires an heuristic approach based on MC simulations (PeresNeto and Olden 2001; Thébaud et al. 2005). The average and the single values obtained for power and type I error estimates of PT were in agreement with those reported by Thébaud et al. (2005). On average, the power of both one-tailed and two-tailed tests was larger than 0.80 , while the type I error was lower than 0.05 , as generally recommended to ensure the trustworthiness of statistical tests (Crawley 2013). The window sizes seemed not to be influential on the estimates of the power and of the type I error, suggesting that PT offer comparable performances regardless of the density of the points included in the set $T$. This is another important aspect differentiating
A



B



D

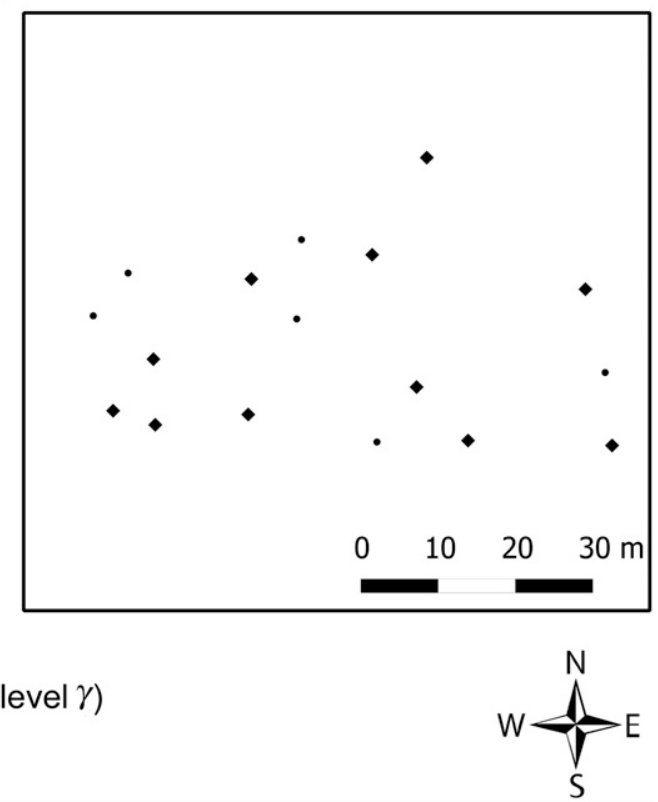

Fig. 2. Maps of chestnut trees of the Vivaio Gambarello orchard carrying at least one nut infected by Gnomoniopsis castanea (level $\gamma$ ) in areas A, C1, B, C2, C, $\mathrm{NC} 1$, and $\mathbf{D}, \mathrm{NC} 2$. 
MDT from the Clark and Evans test, F-, G-, K-, and L-functions. Instead, depending on $n$ and on the tails of the tests, the correlation analysis indicated that the estimates of power were related either to the $m$ number of points included in the subset $I$ (for $\mathrm{P}_{\mathrm{LT}}$ ) or to the

$$
\left(\begin{array}{l}
n \\
m
\end{array}\right)
$$

combinations of the subset $I$ within the set $T$ (for all tests). Although the correlations might have been influenced by the DGP and by the presence of ties, especially in the case of $m$ for $\mathrm{P}_{\mathrm{LT}}$ (Aho 2014), our findings are in agreement with the theory on statistical tests power, despite this theory being developed for a few tests and mostly in a parametric framework (Acutis et al. 2012; Crawley 2013). In fact, the power is generally positively correlated to the sample size and both $m$ and

$$
\left(\begin{array}{l}
n \\
m
\end{array}\right)
$$

are quantities expressing the sample size. Moreover, as expected, the switch from $n=15$ to $n=20$ improved the power of the PT. Under a practical perspective, the $\mathrm{P}_{\mathrm{LT}}$ seems to be endowed with the best performances in terms of power, also when $m$ and

$$
\left(\begin{array}{l}
n \\
m
\end{array}\right)
$$

are relatively small, while $\mathrm{P}_{2 \mathrm{~T}}$ and $\mathrm{P}_{\mathrm{RT}}$ appear to be more reliable when the ratio $m / n$ tends toward $50 \%$. The estimates of type I error do not seem to be a criterion allowing to prefer one test to another according to the sampling size, also considering that the occasional correlations observed did not display a systematic pattern across the $n$ values. Despite the fact that the MC simulations were performed only for PT, they might be considered extendable to the corresponding RT, provided that $B$ is large enough to achieve reliable estimates of $p_{e}$ (Ernst 2004; Jones et al. 2009).

The assessment of power and type I error through MC simulations is a numerical validation, since it is performed on known DGP. The choice of the DGP and the setting of its parameters (e.g., the beta function and its shape parameters $a$ and $b$, the Strauss process, and gamma) are among the main steps to perform MC simulations, whose known drawback relies on the influence on the simulation results (Carsey and Harden 2014; Jones et al. 2009). However, it is worth noting that, despite the fact that different DGP and related parameters were used to perform the PT on the $m=4$ and $n=20$ case, the average power and type I error observed were similar (Tables 4 and 5), suggesting that PT are robust. Furthermore, in the same example, PT showed comparable results across different spatial patterns of the points in the set $T$; thus, they are virtually suitable to be applied in a wide range of situations, encompassing agricultural, forest, and natural ecosystems. Results were also characterized by low variability within PPC and PPD despite the different degrees of departure from randomness driven by the values of the beta function and Strauss point process parameters.

The biological validation is a pivotal step to confirm the performances of a statistical test also in the field (Thébaud et al. 2005). This validation was performed only on the RT in consideration of the above-cited computational constraints. However, the $95 \%$ confidence intervals of $p_{r}$ indicated a good level of accuracy. Considering the combined results of the RT, the points displaying a DR $>0$ within the network of sampling points covering the study area were clustered for $H$. annosum and randomly distributed for $H$. irregulare. Thus, RT provided responses that were consistent among different tails and in agreement with the results obtained by Gonthier et al. (2012), hence confirming the reliability of the RT in field conditions. Moreover, the advantage of performing the RT rather than autocorrelation analysis is intrinsic in the categorical measurement of the variable under investigation. Despite binary categorical variables (e.g., "presence" versus "absence" of the pathogen) being less informative than continuous variables (e.g., DR), their assessment does not require a refined sampling procedure and it can be performed with a substantial reduction of biological and molecular analyses. MDT were designed specifically for the analysis of single levels of a categorical variable, since for continuous ones as well as for counts and for proportions other techniques are already available (e.g., Mantel test, variogram analyses, and Moran's I). However, the conversion of continuous variables into categorical

\begin{tabular}{|c|c|c|c|c|c|c|c|c|c|c|}
\hline \multirow[b]{2}{*}{ Area } & & \multicolumn{9}{|c|}{ Test } \\
\hline & & $\mathrm{P}_{2 \mathrm{~T}}$ & $\mathrm{P}_{\mathrm{LT}}$ & $\mathrm{P}_{\mathrm{RT}}$ & $\mathrm{R}_{2 \mathrm{~T}} B=B_{\text {min }}$ & $\mathrm{R}_{\mathrm{LT}} B=B_{\text {min }}$ & $\mathrm{R}_{\mathrm{RT}} B=B_{\text {min }}$ & $\mathrm{R}_{2 \mathrm{~T}} B=5 \times 10^{2}$ & $\mathrm{R}_{\mathrm{LT}} B=5 \times 10^{2}$ & $\mathrm{R}_{\mathrm{RT}} B=5 \times 10^{2}$ \\
\hline $\begin{array}{l}\mathrm{C} 1 \\
\bar{d}_{0}=21.2 \mathrm{~m}\end{array}$ & $\left(\begin{array}{l}n_{C 1} \\
m_{C 1}\end{array}\right)=\left(\begin{array}{l}14 \\
10\end{array}\right)=1,001$ & $\begin{array}{l}\bar{D}=19.9 \mathrm{~m} \\
p_{e}=0.301\end{array}$ & $\begin{array}{l}\bar{D}=19.9 \mathrm{~m} \\
p_{e}=0.856\end{array}$ & $\begin{array}{l}\bar{D}=19.9 \mathrm{~m} \\
p_{e}=0.145\end{array}$ & $\begin{array}{l}\bar{D}=19.9 \mathrm{~m} \\
p_{r}=0.30 \\
L_{p r}=0.20 \\
U_{p r}=0.41 \\
B_{\text {min }}=77\end{array}$ & $\begin{array}{l}\bar{D}=19.7 \mathrm{~m} \\
p_{r}=0.75 \\
L_{p r}=0.19 \\
U_{p r}=0.99 \\
B_{\text {min }}=4\end{array}$ & $\begin{array}{l}\bar{D}=19.9 \mathrm{~m} \\
p_{r}=0.16 \\
L_{p r}=0.11 \\
U_{p r}=0.21 \\
B_{\min }=217\end{array}$ & $\begin{array}{l}\bar{D}=19.8 \mathrm{~m} \\
p_{r}=0.31 \\
L_{p r}=0.26 \\
U_{p r}=0.32\end{array}$ & $\begin{array}{l}\bar{D}=20.0 \mathrm{~m} \\
p_{r}=0.85 \\
L_{p r}=0.83 \\
U_{p r}=0.88\end{array}$ & $\begin{array}{l}\bar{D}=20.0 \mathrm{~m} \\
p_{r}=0.14 \\
L_{p r}=0.13 \\
U_{p r}=0.18\end{array}$ \\
\hline $\begin{array}{l}\mathrm{C} 2 \\
\bar{d}_{0}=22.3 \mathrm{~m}\end{array}$ & $\left(\begin{array}{l}n_{C 2} \\
m_{C 2}\end{array}\right)=\left(\begin{array}{l}17 \\
9\end{array}\right)=24,310$ & $\begin{array}{l}\bar{D}=21.2 \mathrm{~m} \\
p_{e}=0.5355\end{array}$ & $\begin{array}{l}\bar{D}=21.2 \mathrm{~m} \\
p_{e}=0.7240\end{array}$ & $\begin{array}{l}\bar{D}=21.2 \mathrm{~m} \\
p_{e}=0.2760\end{array}$ & $\begin{array}{l}\bar{D}=21.9 \mathrm{~m} \\
p_{r}=0.75 \\
L_{p r}=0.55 \\
U_{p r}=0.89 \\
B_{\text {min }}=28\end{array}$ & $\begin{array}{l}\bar{D}=22.1 \mathrm{~m} \\
p_{r}=0.57 \\
L_{p r}=0.18 \\
U_{p r}=0.90 \\
B_{\min }=7\end{array}$ & $\begin{array}{l}\bar{D}=21.3 \mathrm{~m} \\
p_{r}=0.22 \\
L_{p r}=0.14 \\
U_{p r}=0.33 \\
B_{\min }=81\end{array}$ & $\begin{array}{l}\bar{D}=21.2 \mathrm{~m} \\
p_{r}=0.59 \\
L_{p r}=0.48 \\
U_{p r}=0.60\end{array}$ & $\begin{array}{l}\bar{D}=21.2 \mathrm{~m} \\
p_{r}=0.73 \\
L_{p r}=0.68 \\
U_{p r}=0.78\end{array}$ & $\begin{array}{l}\bar{D}=21.2 \mathrm{~m} \\
p_{r}=0.26 \\
L_{p r}=0.24 \\
U_{p r}=0.35\end{array}$ \\
\hline $\begin{array}{l}\mathrm{NC} 1 \\
\bar{d}_{0}=18.8 \mathrm{~m}\end{array}$ & $\left(\begin{array}{l}n_{N C 1} \\
m_{N C 1}\end{array}\right)=\left(\begin{array}{l}14 \\
8\end{array}\right)=3,003$ & $\begin{array}{l}\bar{D}=21.5 \mathrm{~m} \\
p_{e}=0.158\end{array}$ & $\begin{array}{l}\bar{D}=21.5 \mathrm{~m} \\
p_{e}=0.088\end{array}$ & $\begin{array}{l}\bar{D}=21.5 \mathrm{~m} \\
p_{e}=0.913\end{array}$ & $\begin{array}{l}\bar{D}=21.5 \mathrm{~m} \\
p_{r}=0.16 \\
L_{p r}=0.12 \\
U_{p r}=0.20 \\
B_{\text {min }}=294\end{array}$ & $\begin{array}{l}\bar{D}=21.5 \mathrm{~m} \\
p_{r}=0.08 \\
L_{p r}=0.06 \\
U_{p r}=0.10 \\
B_{\text {min }}=493\end{array}$ & $\begin{array}{l}\bar{D}=21.8 \mathrm{~m} \\
p_{r}=0.75 \\
L_{p r}=0.19 \\
U_{p r}=0.99 \\
B_{\text {min }}=4\end{array}$ & $\begin{array}{l}\bar{D}=21.5 \mathrm{~m} \\
p_{r}=0.16 \\
L_{p r}=0.14 \\
U_{p r}=0.19\end{array}$ & $\begin{array}{l}\bar{D}=21.5 \mathrm{~m} \\
p_{r}=0.08 \\
L_{p r}=0.07 \\
U_{p r}=0.11\end{array}$ & $\begin{array}{l}\bar{D}=21.5 \mathrm{~m} \\
p_{r}=0.90 \\
L_{p r}=0.88 \\
U_{p r}=0.92\end{array}$ \\
\hline $\begin{array}{l}\mathrm{NC} 2 \\
\bar{d}_{0}=32.7 \mathrm{~m}\end{array}$ & $\left(\begin{array}{l}n_{N C 2} \\
m_{N C 2}\end{array}\right)=\left(\begin{array}{l}17 \\
11\end{array}\right)=12,376$ & $\begin{array}{l}\bar{D}=31.6 \mathrm{~m} \\
p_{e}=0.6534\end{array}$ & $\begin{array}{l}\bar{D}=31.6 \mathrm{~m} \\
p_{e}=0.6509\end{array}$ & $\begin{array}{l}\bar{D}=31.6 \mathrm{~m} \\
p_{e}=0.3491\end{array}$ & $\begin{array}{l}\bar{D}=31.4 \mathrm{~m} \\
p_{r}=0.39 \\
L_{p r}=0.20 \\
U_{p r}=0.81 \\
B_{\text {min }}=23\end{array}$ & $\begin{array}{l}\bar{D}=31.7 \mathrm{~m} \\
p_{r}=0.67 \\
L_{p r}=0.30 \\
U_{p r}=0.92 \\
B_{\text {min }}=9\end{array}$ & $\begin{array}{l}\bar{D}=31.5 \mathrm{~m} \\
p_{r}=0.23 \\
L_{p r}=0.10 \\
U_{p r}=0.40 \\
B_{\text {min }}=35\end{array}$ & $\begin{array}{l}\bar{D}=31.6 \mathrm{~m} \\
p_{r}=0.60 \\
L_{p r}=0.59 \\
U_{p r}=0.65\end{array}$ & $\begin{array}{l}\bar{D}=31.8 \mathrm{~m} \\
p_{r}=0.65 \\
L_{p r}=0.60 \\
U_{p r}=0.71\end{array}$ & $\begin{array}{l}\bar{D}=31.6 \mathrm{~m} \\
p_{r}=0.35 \\
L_{p r}=0.29 \\
U_{p r}=0.41\end{array}$ \\
\hline
\end{tabular}
ones is normally possible once a threshold has been fixed (Hosmer

TABLE 6. Output of the mean distance tests for areas $\mathrm{C} 1, \mathrm{C} 2, \mathrm{NC} 1$, and $\mathrm{NC}^{\mathrm{a}}$


lower $\left(L_{p r}\right)$ and upper $\left(U_{p r}\right)$ bounds of its $95 \%$ confidence interval. For randomization tests, the output is divided according to the number $B$ of combinations randomly selected to perform the tests, including the estimate of the minimum acceptable value of $B\left(B_{\min }\right)$. The observed mean value of the triangular Euclidean distance matrix among the $m$ out of $n$ chestnut trees carrying at least one infected nut $\left(\bar{d}_{0}\right)$ and the number of possible combinations $\left(\begin{array}{l}n \\ m\end{array}\right)$ are reported for each area. 
and Lemeshow 1989). The choice of the threshold for categorical coding is a crucial issue (Hosmer and Lemeshow 1989) and it should be based on biologically relevant information, as shown here for the case study of Gonthier et al. (2012), since different codings could result in changes of the detected spatial pattern.

The application of the MDT to the case study of the nut rot caused by $G$. castanea showed a possible way through which the designed geostatistical tests can be performed to gather information about a plant disease. Regardless of the area where the tests were performed, all MDT agreed in the identification of a random spatial pattern of the chestnut trees displaying the presence of G. castanea. Since in half of the areas chestnuts were clustered, while in the other half they were not, it could be argued that the plantation density is not a variable influencing the spatial distribution of the pathogen. This conclusion seems to be confirmed by the absence of significant differences among the incidences of the pathogen among the areas. Therefore, the choice of the plantation density, which is a relevant issue for chestnut growers (Dong-Sheng et al. 2009), can be based on other parameters (e.g., yield productivity and intraspecific competition) rather than on the risk of transmission of $G$. castanea among neighboring trees. This finding is relevant since, to date, very little was known about the relationship between the management practices and the incidence of $G$. castanea. However, further analyses are needed to determine the factors influencing the observed spatial patterns, since the infection pathways of $G$. castanea are still mainly unknown (Lione et al. 2015).

Although the MDT approach is proposed here in the framework of plant pathology, if the assumptions about the stochasticity of the processes under investigation are fulfilled, no constraints arise for its broader application in other research fields (e.g., ecology, forestry, and economy). Finally, the availability of accessible R algorithms and of a "point-and-click" software should facilitate the use of the MDT also among users lacking specific background in advanced statistics.

\section{ACKNOWLEDGMENTS}

This study was partially supported by grants of Regione Piemonte through the activity of the Chestnut Growing Centre and of the University of Torino (60\%). We thank the anonymous referees that improved the quality of the paper with their suggestions and M. Garbelotto of the Department of Environmental Science, Policy and Management of UC Berkeley for providing the hardware to run part of the MC simulations.

\section{LITERATURE CITED}

Acutis, M., Scaglia, B., and Confalonieri, R. 2012. Perfunctory analysis of variance in agronomy, and its consequences in experimental results interpretation. Eur. J. Agron. 43:129-135.

Aho, K. A. 2014. Foundational and Applied Statistics for Biologists Using R. CRC Press, Boca Raton, FL.

Aldenderfer, M. S., and Blashfield, R. K. 1987. Cluster Analysis. SAGE Publications, London, UK.

Beeley, C. 2013. Web Application Development with R Using Shiny. Packt Publishing Ltd., Birmingham, UK.

Boots, B. 2003. Developing local measures of spatial association for categorical data. J. Geogr. Syst. 5:139-160.

Carsey, T. M., and Harden, J. J. 2014. Monte Carlo Simulation and Resampling Methods for Social Science. Sage Publications, Thousand Oaks, CA.

Chellemi, D. O., Rohrbach, K. G., Yost, R. S., and Sonoda, R. M. 1988. Analysis of the spatial pattern of plant pathogens and diseased plants using geostatistics. Phytopathology 78:221-226.

Clark, P. J., and Evans, F. C. 1954. Distance to the nearest neighbor as a measure of spatial relationship in populations. Ecology 35:445-453.

Crawley, M. J. 2013. The R Book, 2nd ed. John Wiley and Sons Ltd., Chichester, UK.

de Smith, M. J., Goodchild, M. F., and Longley, P. 2007. Geospatial Analysis: A Comprehensive Guide to Principles, Techniques and Software Tools. Troubador Publishing Ltd., Leicester, UK.

Dong-Sheng, Y., Ya-Li, H., Rui-Dong, T., Lin, Q., and Hong-Wen, H. 2009. The cultivation techniques of compactly planted chestnut (Castanea mollissima B1.) for early fruiting and high yield. Acta Hortic. 844:465.
Ernst, M. 2004. Permutation methods: A basis for exact inference. Stat. Sci. 19:676-685.

Ferrandino, F. J. 1998. Past nonrandomness and aggregation to spatial correlation: 2DCORR, a new approach for discrete data. Phytopathology 88:84-91.

Gonthier, P., Anselmi, N., Capretti, P., Bussotti, F., Feducci, M., Giordano, L., Honorati, T., Lione, G., Luchi, N., Michelozzi, M., Paparatti, B., Sillo, F., Vettraino, A. M., and Garbelotto, M. 2014. An integrated approach to control the introduced forest pathogen Heterobasidion irregulare in Europe. Forestry 87:471-481.

Gonthier, P., Lione, G., Giordano, L., and Garbelotto, M. 2012. The American forest pathogen Heterobasidion irregulare colonizes unexpected habitats after its introduction in Italy. Ecol. Appl. 22:2135-2143.

Good, P. 2000. Permutation Tests-A Practical Guide to Resampling Methods for Testing Hypotheses. 2nd ed. Springer-Verlag, New York.

Goslee, S. C., and Urban, D. L. 2007. The ecodist package for dissimilaritybased analysis of ecological data. J. Stat. Softw. 22:1-19.

Gottwald, T. R., Avinent, L., Llácer, G., de Mendoza, A. H., and Cambra, M. 1995. Analysis of the spatial spread of sharka (Plum pox virus) in apricot and peach orchards in eastern Spain. Plant Dis. 79:266-278.

Gray, S. M., Moyer, J. W., and Bloomfield, P. 1986. Two-dimensional distance class model for quantitative description of virus-infected plant distribution lattices. Phytopathology 76:243-248.

Hartwig, F. P. 2013. Two-tailed $P$ values calculation in permutation-based tests: A warning against "asymptotic bias" in randomized clinical trials. J. Clin. Trials 3:145.

Hosmer, D. W., and Lemeshow, S. 1989. Applied Logistic Regression. John Wiley and Sons, New York.

Jaime-Garcia, R., Trinidad-Correa, R., Felix-Gastelum, R., Orum, T. V., Wasmann, C. C., and Nelson, M. R. 2000. Temporal and spatial patterns of genetic structure of Phytophthora infestans from tomato and potato in the Del Fuerte Valley. Phytopathology 90:1188-1195.

Jones, O., Maillardet, R., and Robinson, A. 2009. Introduction to Scientific Programming and Simulation Using R. CRC Press, Boca Raton, FL.

Lamichhane, J. R., Fabi, A., Ridolfi, R., and Varvaro, L. 2013. Epidemiological study of hazelnut bacterial blight in central Italy by using laboratory analysis and geostatistics. PLoS One 8:e56298.

Lione, G., Giordano, L., Sillo, F., and Gonthier, P. 2015. Testing and modelling the effects of climate on the incidence of the emergent nut rot agent of chestnut Gnomoniopsis castanea. Plant Pathol. 64:852-863.

Mantel, N. 1967. The detection of disease clustering and a generalized regression approach. Cancer Res. 27:209-220.

Marchant, B. P., and Lark, R. M. 2004. Estimating variogram uncertainty. Math. Geol. 36:867-898.

Micciolo, R., Espa, G., and Canal, L. 2013. Ricerca Con R-Metodi Di Inferenza Statistica. Apogeo, Milano, Italy.

Mitchell, A. 2009. The ESRI Guide to GIS Analysis. Volume 2. Spatial Measurements and Statistics. Environmental Systems Research Institute Press, Redlands, CA.

Nelson, M. R., Orum, T. V., Jaime-Garcia, R., and Nadeem, A. 1999. Applications of geographic information systems and geostatistics in plant disease epidemiology and management. Plant Dis. 83:308-319.

Nelson, S. C. 1995. STCLASS-spatiotemporal distance class analysis software for the personal computer. Plant Dis. 79:643-648.

Nelson, S. C., Marsh, P., and Campbell, C. 1992. 2DCLASS, a two-dimensional distance class analysis software for the personal computer. Plant Dis. 76:427-432.

Peres-Neto, P. R., and Olden, J. D. 2001. Assessing the robustness of randomization tests: Examples from behavioural studies. Anim. Behav. 61:79-86.

Perry, J. N., and Hewitt, M. 1991. A new index of aggregation for animal counts. Biometrics 47:1505-1518.

Pizzato, J. A., Araújo, D. V., Galvanin, E. A., Júnior, J. R., Matos, Â. N., Vecchi, M., and Zavislak, F. D. 2014. Geostatistics as a methodology for studying the spatiotemporal dynamics of Ramularia areola in cotton crops. Am. J. Plant Sci. 5:2472-2479.

Strauss, D. J. 1975. A model for clustering. Biometrika 63:467-475.

Szmyt, J. 2014. Spatial statistics in ecological analysis: From indices to functions. Silva Fenn. 48:1-31.

Thébaud, G., Peyrard, N., Dallot, S., Calonnec, A., and Labonne, G. 2005. Investigating disease spread between two assessment dates with permutation tests on a lattice. Phytopathology 95:1453-1461.

Visentin, I., Gentile, S., Valentino, D., Gonthier, P., Tamietti, G., and Cardinale, F. 2012. Gnomoniopsis castanea sp. nov. (Gnomoniaceae, Diaporthales) as the causal agent of nut rot in sweet chestnut. J. Plant Pathol. 94:411-419.

Webster, R., and Oliver, M. A. 2001. Geostatistics for Environmental Scientists. John Wiley and Sons Ltd., Chichester, UK.

Weidong, L. 2006. Transiogram: A spatial relationship measure for categorical data. Int. J. Geogr. Inf. Sci. 20:693-699.

Wigginton, J. E., Cutler, D. J., and Abecasis, G. R. 2005. A note on exact tests of Hardy-Weinberg equilibrium. Am. J. Hum. Genet. 76:887-893. 